\title{
Exploratory Study on the Extended Teaching of Mechanical Knowledge in Measurement and Control Major
}

\author{
Yong Qin \\ College of Measurement and Control Technology and \\ Communications Engineering \\ University of Science and Technology \\ Harbin, China \\ qinyong@ @rbust.edu.cn
}

\author{
Erliang Liu \\ School of Mechanical \& Power Engineering \\ University of Science and Technology \\ Harbin, China \\ elliu@hrbust.edu.cn
}

\begin{abstract}
Precision Mechanical Design is a professional basic course for students majored in measuring and controlling technology. Combined the practical content of engineering application, this paper discusses the needs in the development of precision machinery design courses. The exploratory research and application of the teaching method of mechanical knowledge extensions are carried out in the major of measuring and controlling technology. In this paper, our students conduct extensive training on mechanical knowledge from the extended teaching knowledge in classroom to drawing homework after class. Through teachers' knowledge guidance and the sharing of mechanical design results, students can have a deeper understanding of the principles and structures of machinery. Students' design desire is aroused. After years of exploration in the extended teaching, students' application ability of mechanical knowledge in practice has been improved. This paper puts forward reasonable and useful ideas for the development of engineering education.
\end{abstract}

Keywords-Extended teaching; Precision machinery design; Measure and control technology; Teaching reform

\section{INTRODUCTION}

The measurement and control technology major should focus on the cultivation of compound application-oriented talents [1-2]. Graduation goal is that students are able to applied mathematics, physics, electrical, optical, and the basic principle of the mechanical engineering and related professional knowledge to recognize and express complex engineering problems in measurement and control major. Through research and analysis, students could obtain effective conclusion to solve these problems. In order to achieve this goal, students should be familiar with the basic structure and control principle of equipment. It requires that the mechanical movement principle can be understood and familiar. Then mastery of knowledge is very important for mechanical knowledge. There are 47 professional courses in our university. In addition to basic courses, there are 33 specialized courses related to electronic circuits, signal processing and instrument design. However, there are three courses involved in mechanical engineering, such as engineering drawing, precision design foundation, and instrument manufacturing

The plan of "13th Five-Year" in Education Science of 2016 record project in Heilongjiang (GJC316095). technology. This makes students' basic mechanical knowledge weak in the measurement and control profession. In the requirements of engineering comprehensive talents, our training objective is to hope that students can fully demonstrate their abilities in the post of graduation. In the existing conditions, how to make up the students' weak links, improve the students' engineering practical ability, strengthen training students' engineering ability and innovation ability, this has always been one of our teaching and research direction. It is great significance and application value for strengthening the engineering ability and innovation ability of students. This enables students to better adapt to the needs of current employment and engineering applications. It is always the goal of university education which will cultivate applicationoriented talents suitable for engineering needs.

\section{OBJECT OF RESEARCH}

Precision mechanical design is a professional basic course for profession of measuring and controlling technology and instrument, and it have explicit theoretical and practical characteristic. By studying the course, firstly, structure, principle, performance characteristics, and basic design and calculation method of common components and parts in the precision machinery will be researched. Secondly, basic theoretical knowledge, national standard, and other materials will be obtained. The Course of Precision Mechanical Design includes class teaching, experimental teaching and Comprehensive Curriculum Design. As the teaching teacher, I hope to strengthen students' mechanical design ability through teaching, experiment and Curriculum Design. Based on the measurement and control technology background, the teaching work of precision machinery design course is completed with engineering application ability as the target. In different teaching links, students should be trained in the practical skills of engineering machinery. By improving students' understanding of mechanical structure, we can strengthen students' ability of drawing reading, drawing and designing. The major of measurement and control technology has the professional advantages of electronic circuit design in our university. The combination of electronic circuit and mechanical design, through the development of cross science, 
can give play to the greater advantages of the discipline major, and will achieve better results in the study and employment of students. This not only lays a foundation for students' theoretical and practical ability, but also provides support for the spirit of innovation and entrepreneurial vitality. From the student's point of view can promote the academic progress, promotes the student employment. From the perspective of measurement and control technology major, promoting engineering education will able to promote the innovation and reform of first-class specialty.

\section{METHOD OF RESEARCH}

In the process of expanding the teaching of mechanical knowledge, the research method is mainly based on the teaching of basic knowledge and supplemented by the practical application. In the process of classroom teaching, it mainly tells the knowledge of mechanical parts and mechanism on the basis of the previous basic course of engineering drawing. Through understanding the principle, structure and application of mechanical parts, students can further understand the motion form of mechanical mechanism and establish basic mechanical design concepts. While teaching the knowledge points in the textbook, students are also given corresponding design tasks, such as using drawing tools to complete the design of the simple parts. Students completed the design work, while mastered the basic operation of the drawing software, such as the design of 3D parts and the transformation of the engineering drawing. Through the knowledge teaching in class and the completion of homework, students can further enhance their knowledge mastery and application. It also lays a foundation for the subsequent curriculum design and application. In the whole teaching process of precision machinery design course, different teaching methods are adopted according to different teaching contents and forms.

\section{A. Classroom knowledge and expanding knowledge}

Long-term accumulation and study of teaching content is the basic guarantee of a good lesson [3]. Classroom teaching knowledge and exercises are traditional teaching methods. Practicing the exercises can help students deepen the impression of the knowledge for the content in class [4]. However, this is only the content in the textbook, and there is still a certain gap between the content and the actual engineering problems. Students should master the basic knowledge the course. In the teaching process, teachers can pass the accumulated project experience to students through the teaching process of classroom teaching, such as some design skills, solving practical problems and so on. In the process of expressing the solution of practical project problems, students' attention can be easier concentrated and their interest can be aroused. It will help students to have a more solid grasp of the knowledge they have learned. This creates a good cycle.

This kind of teaching method has high requirements for teaching teachers, who need to have rich experience in mechanical design.

\section{B. The drawing assignment after class}

Students are given a drawing assignment after class. Teachers send the collected part drawings to the students, and then every student will independently complete the 3D part drawings of theirs selected parts. It also includes the marking of the $3 \mathrm{~d}$ part drawing into engineering drawing, dimension and tolerance marking. In this drawing assignment, it is recommended that students master a kind of computer-aided design software, such as AutoCAD, SolidWorks, UG and other drawing tools. This gives students a chance to know the practical engineering application. Moreover, they have mastered the basic process of building 3D models, assembling systems and converting engineering drawings by drawing software.

It is very important to apply the knowledge learned in class to the practical design, and it is also one of our teaching objectives.

\section{Share research results}

As a teaching teacher, I also need to keep learning and enhance my mechanical design ability. The instructor shared his mechanical design materials with the students. These materials include parts library, equipment model design, and other mechanical design. These data is shared to the students through the Internet disk. Lessons during the project research are also shared with students.

Students make use of network resources to enrich their mechanical knowledge after class. They can enjoy mechanical design by sharing technical materials and research results with teachers.

The practical engineering experience of teachers can give students effective guidance in the course design. Some useful suggestions can also be given to guide students to participate in the innovation design competition or graduation design.

\section{Ability development of curriculum practice}

The course practice content runs through the whole teaching process. The previous teaching content is the process of cultivating the practical ability. The course design in the later period of the course is to perfect and summarize the whole teaching content [5-6].

In the course practice, some students are interested in some subjects. They have some new ideas and innovative thinking to them. And then they can propose their own design topics and carry out the design after the review by the instructor. In this way, we can overcome the shortcoming of short course design cycle and insufficient knowledge reserve. It can give full play to students' initiative. It can also make full use of students' interest and spare time to expand the course practice.

The course design of precision mechanical design usually choose general-purpose precision mechanical transmission device as a design object. The design content should cover the main course content. Through the course design, students can consolidate and comprehensively apply the theoretical knowledge learned in this course. Through the curriculum and the needs of students' skills to work in the future were analyzed, and the course design of selected topic focuses on the structure is compact, high precision, lightweight, flexible operation instrument design. In order to meet the future work demands of the students, the course design strengthens the precision design 
and structure design, and desalinates the heavy load and strength check of mechanical parts.

In the course practice, with the aid of teaching reform, we will purchase many kinds of mechanical measuring instruments and tools, such as percent meter, umbrella opener, thickness gauge, theodolite, the microscope and other precision instruments. These instruments and equipment can be disassembled and analyzed by students, as shown in Figure 1.

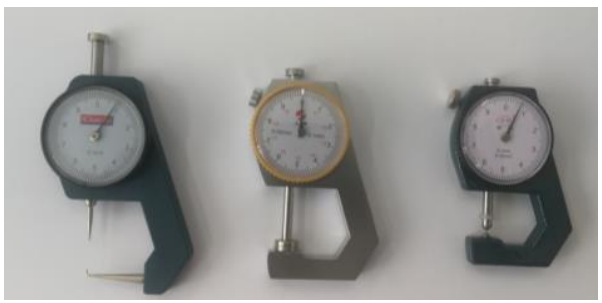

a) Thickness gauges of different structures

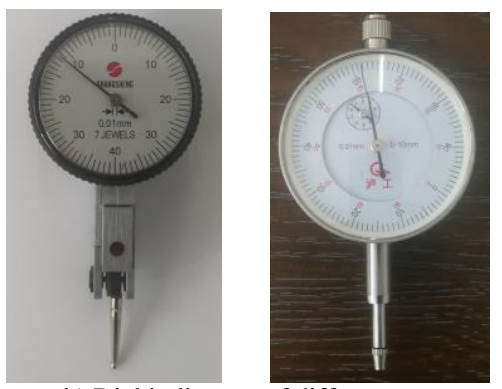

b) Dial indicators of different structure

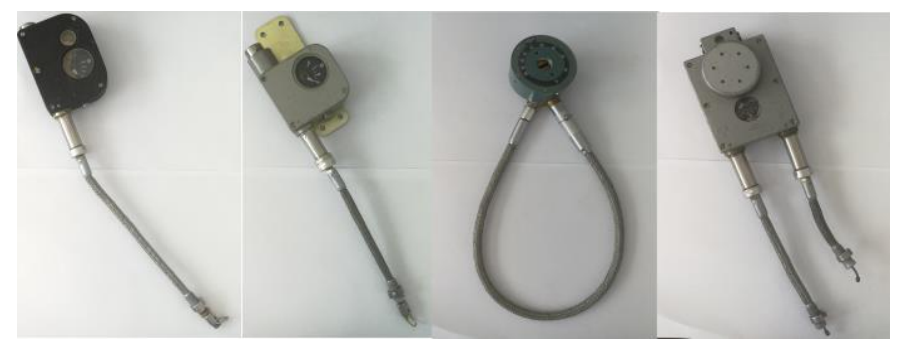

c) Parachute opening device with different structure

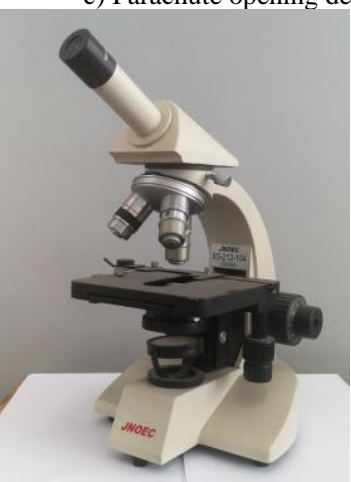

d) The microscope

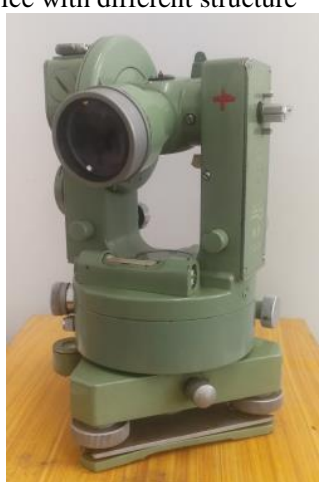

e) The odolite
Fig. 1 Measuring instruments are used in course practice

Course design should include teaching content. The content includes mechanical structure, transmission design, precision check, structural design, tolerance coordination, material selection, mechanical drawing, etc. These can basically cover contents of the course. The overall difficulty of course design is moderate. Course practice provides students with more practical experience and enriches students' practical knowledge and experience.
The overall framework of research on extensions teaching of mechanical knowledge is shown in figure 2.

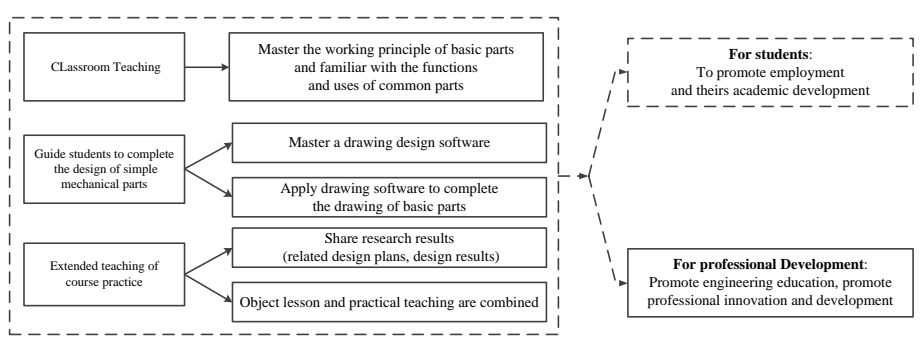

Fig. 2 The overall framework of research on extensions teaching of mechanical knowledge

\section{STUDENT ACHIEVEMENT DISPLAY}

Students learn the use of 3D drawing software by themselves after class. Starting from the practical engineering application, students can use the drawing software to complete the building of 3D models of parts, transformation of engineering drawings and others works. The convenience of drawing software is that it can more directly observe the parts. In the three-dimensional environment, it is easier to understand the mechanism movement principle and judge whether there is interference among the parts. Mechanical analysis and structural simulation can be completed by the drawing software. This will greatly improve the measurement and control technology major students the weak links of the "machine" aspect. From 2014 to 2017, we completed four rounds of mechanical extended teaching. Some achievements have been made in the research process of extensions teaching of mechanical knowledge in the major of measurement and control technology. Students have a deeper understanding of mechanical design than previous. Figure 3 shows the learning results of students' homework after class.

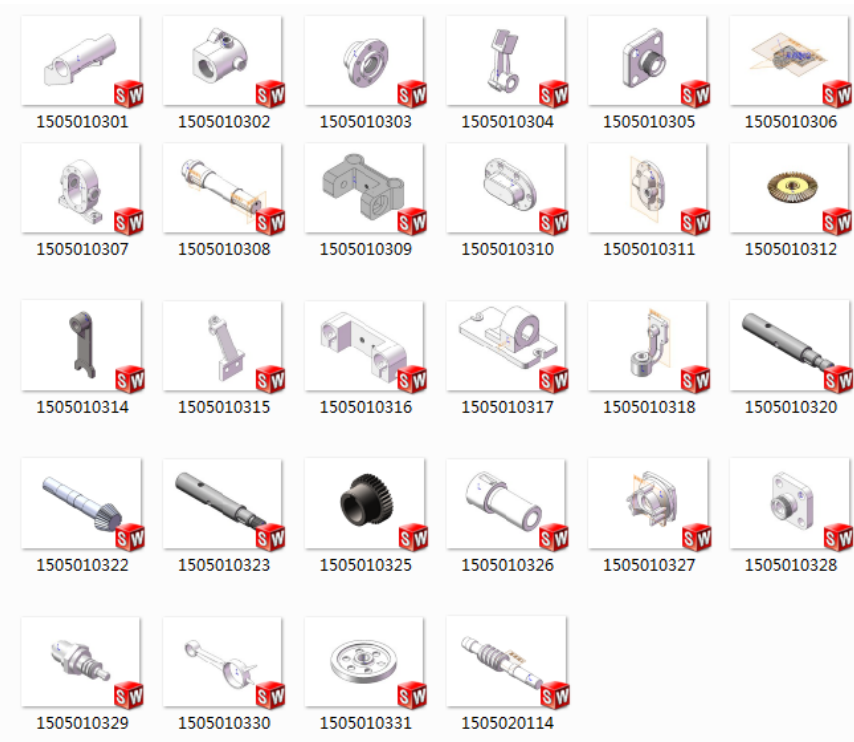

Fig. 3 students' drawing homework after class

Figure 4 showed a model of the dial indicator completed during the course design 


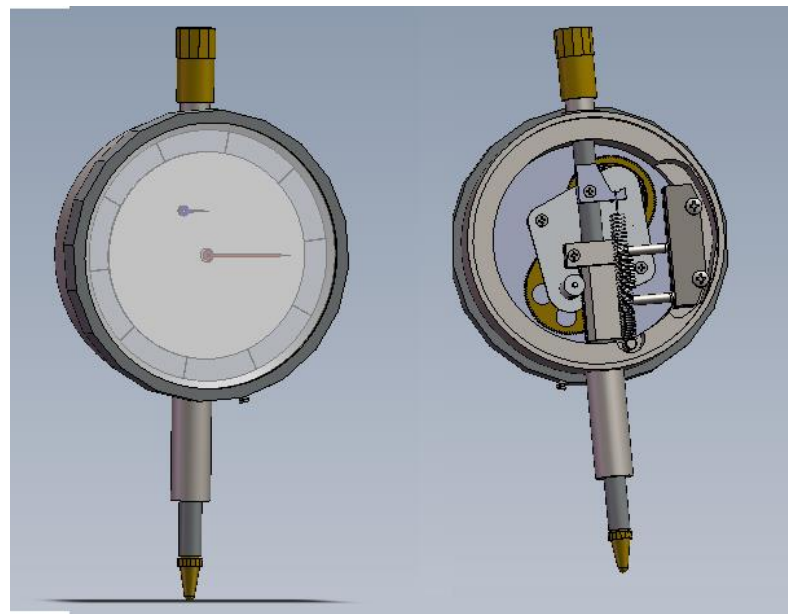

Fig. 4 A dial indicator model

Extended teaching methods are adopted in the teaching process of the precision machinery design course. And certain teaching achievements have been made. Students of measurement and control technology major achieved outstanding results in college students' innovative experiment, undergraduates innovative design competition and so on. Mechanical knowledge has been flexibly used in these activities.

\section{V.CONCLUSION}

The mechanical knowledge extensions teaching of measurement and control major is based on the course of precision machinery design. Students gradually deepen their understanding of mechanical knowledge in the teaching process. Students' mechanical design ability has been improved through years of continuous exploration and research in classroom teaching, homework training and the development of mechanical knowledge. This will lay a foundation for students' future engineering practice and application. This project will continue to explore in the subsequent teaching process, improve the teaching content, summarize the teaching methods, and make continuous efforts to improve the students' engineering application ability.

\section{ACKNOWLEDGMENT}

The plan of "13th Five-Year" in Education Science of 2016 record project in Heilongjiang (GJC316095).

\section{REFERENCES}

[1] CAI Jian-wen, PAN Xue-tao, ZHANG Mei-feng, etc. "Personnel Training Mode of Measurement and Control Technology and Instrument Specialty in Local Colleges", Journal of Electrical \& Electronic Education, vol.38, issue 2, pp. 25-28, 2016. (In Chinese)

[2] LU Yi-xin,LI Yuan-yuan,YANG Sen-lin . "On creative education culture mode in measurement-control technology and instrument" Journal of Xi'an University of Posts and Telecommunications, vol.16, No. S2, pp. 100-102, Dec. 2011. (In Chinese)

[3] Wang haibo, Gao peng, Qin xiangyang, Li Minghua, Sun xiaoli, "Analysis of the ability to improve in-class teaching methods", Basic Medical Education, vol.16, No. 11, pp. 929-932, Nov. 2014. (In Chinese)

[4] MAO Cuili ZHOU Xianhui, "Exploration and Practice of Comprehensive Training mode of Measurement and Control Technology", No.8, pp.33-35, Aug. 2013. (In Chinese)

[5] ZHOU Yi-lin, YAO Yan, Lu Mei-yu, "Reform and practice on the curriculum design of precision machinery and equipment in measurement and control major", LABORATORY SCIENCE, vol.14, pp. 63-65, April 2011. (In Chinese)

[6] Liu Yudi, "Facilitating the development of our university's measurement \& control Technology specialty with the reform of practical teaching", Journal of Xi' an Aeronautical University, vol. 33, No. 5, pp. 7-9 September 2015. (In Chinese) 